\title{
Prevalence of antimicrobial-resistant pathogens in Canadian hospitals: Results of the Canadian Ward Surveillance Study (CANWARD 2007)
}

\author{
George G Zhanel PhD $D^{1,2,3}$, James A Karlowsky PhD ${ }^{1,3}$, Mel DeCorby MSc ${ }^{1,3}$, Kim A Nichol MSc ${ }^{3}$, \\ Aleksandra Wierzbowski MSc ${ }^{1,3}$, Patricia J Baudry MSc $\mathrm{MS}^{1,3}$, Philippe Lagacé-Wiens $\mathrm{MD}^{1,3}$, Andrew Walkty $\mathrm{MD}^{1,3}$, \\ Frank Schweizer $\mathrm{PhD}^{4}$, Heather Adam $\mathrm{PhD}^{5}$, Melissa McCracken $\mathrm{MSc}^{6}$, Michael R Mulvey $\mathrm{PhD}^{6}$, \\ The Canadian Antimicrobial Resistance Alliance (CARA), Daryl J Hoban PhD ${ }^{1,3}$
}

GG Zhanel, JA Karlowsky, M DeCorby, et al. Prevalence of antimicrobial-resistant pathogens in Canadian hospitals: Results of the Canadian Ward Surveillance Study (CANWARD 2007). Can J Infect Dis Med Microbiol 2009;20(Suppl A):9A-19A.

BACKGROUND: Canadian hospitals as well as hospitals worldwide are increasingly faced with antibiotic-resistant pathogens, including multidrug-resistant (MDR) strains.

OBJECTIVES: To assess the prevalence of pathogens, including the resistance genotypes of methicillin-resistant Staphylococcus aureus (MRSA), vancomycin-resistant enterococci (VRE) and extendedspectrum beta-lactamase (ESBL)-producing Escherichia coli in Canadian hospitals, as well as their antimicrobial resistance patterns.

METHODS: Bacterial isolates were obtained between January 1, 2007, and December 31, 2007, inclusive, from patients in 12 hospitals across Canada as part of the Canadian Ward Surveillance Study (CANWARD 2007). Isolates were obtained from bacteremic, urinary, respiratory and wound specimens and underwent antimicrobial susceptibility testing. Susceptibility testing was assessed using the Clinical and Laboratory Standards Institute broth microdilution method.

RESULTS: In total, 7881 isolates were recovered from clinical specimens of patients attending Canadian hospitals. The 7881 isolates were collected from respiratory $(n=2306 ; 29.3 \%)$, blood $(n=3631 ; 46.1 \%)$, wounds/tissue $(n=617 ; 7.8 \%)$ and urinary $(n=1327 ; 16.8 \%)$ specimens. The 10 most common organisms isolated from $76.5 \%$ of all clinical specimens were E coli (21.6\%), methicillin-susceptible S aureus (13.9\%), Streptococcus pneumoniae (8.9\%), Pseudomonas aeruginosa (8.0\%), Klebsiella pneumoniae (5.8\%), MRSA (4.9\%), Haemophilus influenzae $(4.3 \%)$, coagulase-negative staphylococci/Staphylococcus epidermidis (4.0\%), Enterococcus species (3.0\%) and Enterobacter cloacae (2.1\%). MRSA made up 26.0\% (385 of 1480) of all S aureus (genotypically, $79.2 \%$ of MRSA were health care-associated MRSA and $19.5 \%$ were community-associated MRSA), and VRE made up $1.8 \%$ of all enterococci $(62.5 \%$ of VRE had the vanA genotype). ESBLproducing $E$ coli occurred in $3.4 \%$ of $E$ coli isolates. The CTX-M type was the predominant ESBL, with CTX-M-15 as the predominant genotype. With MRSA, no resistance was observed to daptomycin, agents were: clarithromycin $91.4 \%$, clindamycin $61.8 \%$, fluoroquinolones $88.6 \%$ to $89.6 \%$, and trimethoprim-sulfamethoxazole $12.2 \%$. With E coli, no resistance was observed to ertapenem, meropenem and tigecycline, while resistance rates to other agents were: amikacin $0.1 \%$, cefazolin $14.2 \%$, cefepime $2.0 \%$, ceftriaxone $8.9 \%$, gentamicin $10.6 \%$, fluoroquinolones $23.6 \%$ to $24.5 \%$, piperacillin-tazobactam $1.3 \%$ and trimethoprim-sulfamethoxazole $26.6 \%$. Resistance rates linezolid, tigecycline and vancomycin, while resistance rates to other

with $P$ aeruginosa were: amikacin $7.6 \%$, cefepime $11.7 \%$, gentamicin $20.8 \%$, fluoroquinolones $23.4 \%$ to $25.1 \%$, meropenem $8.1 \%$ and piperacillin-tazobactam $7.3 \%$. A MDR phenotype (resistance to three or more of cefepime, piperacillin-tazobactam, meropenem, amikacin or gentamicin, and ciprofloxacin) occurred frequently in $P$ aeruginosa (10.6\%) but uncommonly in E coli $(1.2 \%), \mathrm{K}$ pneumoniae $(1.5 \%)$, E cloacae (0\%) or H influenzae (0\%).

CONCLUSIONS: E coli, $S$ aureus (methicillin-susceptible and MRSA), $S$ pneumoniae, $P$ aeruginosa, $K$ pneumoniae, $H$ influenzae and Enterococcus species are the most common isolates recovered from clinical specimens in Canadian hospitals. The prevalence of MRSA was 26.0\% (of which genotypically, $19.5 \%$ was community-associated MRSA), while VRE and ESBL-producing E coli occurred in $1.8 \%$ and $3.4 \%$ of isolates, respectively. A MDR phenotype is common with $P$ aeruginosa in Canadian hospitals.

Key Words: Canadian hospitals; Resistance; Surveillances

\section{La prévalence des pathogènes résistant aux antimicrobiens dans les hôpitaux canadiens : Les résultats de l'étude CANWARD 2007 sur la surveillance des services aux hospitalisés canadiens}

HISTORIQUE : Les hôpitaux nord-américains et du monde entier affrontent de plus en plus des pathogènes résistant aux antibiotiques, y compris des souches multirésistantes.

OBJECTIFS : Évaluer la prévalence des pathogènes, y compris la résistance des génotypes du staphylocoque doré méthicillinorésistant (SARM), des entérocoques résistant à la vancomycine (ERV) et de l'Escherichia coli producteur de bêta-lactamase à large spectre (BLLS) dans les hôpitaux canadiens, ainsi que leurs modes de résistance antimicrobienne.

MÉTHODOLOGIE : On a obtenu les isolats bactériens entre le $1^{\mathrm{er}}$ janvier et le 31 décembre 2007, inclusivement, auprès de patients de 12 hôpitaux du Canada dans le cadre de l'étude CANWARD 2007 sur la surveillance des services aux hospitalisés canadiens. On a prélevé les isolats dans des échantillons bactériémiques, urinaires, respiratoires et de plaies, qui ont subi un test de susceptibilité aux antimicrobiens. On a évalué ce test au moyen de la méthode de microdilution en milieu liquide du Clinical and Laboratory Standards Institute.

RÉSULTATS : On a prélevé au total 7881 isolats d'échantillons cliniques de patients qui fréquentaient des hôpitaux canadiens. Ces 7881 isolats ont été prélevés sur des échantillons respiratoires $(n=2 \quad 306$;

suite page suivante

${ }^{1}$ Department of Medical Microbiology, Faculty of Medicine; ${ }^{2}$ Departments of Medicine and ${ }^{3}$ Clinical Microbiology, Health Sciences Centre;

${ }^{4}$ Department of Chemistry, Faculty of Science, University of Manitoba, Winnipeg, Manitoba; ${ }^{5}$ University of Toronto, Toronto, Ontario;

${ }^{6}$ Nosocomial Infections Branch, National Microbiology Laboratory, Winnipeg, Manitoba

Correspondence: Dr George G Zhanel, Clinical Microbiology, Health Sciences Centre, MS673-820 Sherbrook Street, Winnipeg, Manitoba,

R3A 1R9. Telephone 204-787-4902, fax: 204-787-4699, e-mail ggzhanel@pcs.mb.ca 
$29,3 \%$ ), sanguins ( $\mathrm{n}=3631 ; 46,1 \%$ ), de plaies ou de tissus ( $\mathrm{n}=617 ; 7.8 \%$ ) et urinaires $(n=1327 ; 16,8 \%)$. Les dix principaux organismes isolés dans $76,5 \%$ de tous les échantillons cliniques étaient l'E coli (21,6\%), le staphylocoque doré susceptible à la méthicilline $(13,9 \%)$, le Streptococcus pneumoniae $(8,9 \%)$, le Pseudomonas aeruginosa (8,0 \%), le Klebsiella pneumoniae (5,8 \%), le SRAM (4,9\%), l'Haemophilus influenzae (4,3\%), les staphylocoques négatifs à la coagulase ou le Staphylococcus epidermidis $(4,0 \%)$, les espèces d'entérocoques $(3,0 \%)$ et l'Enterobacter cloacae $(2,1 \%)$. Le SRAM représentaient 26,0\% (385 des 1480 échantillons) de tous les staphylocoques dorés (d'un point de vue génotypique, 79,2\% des SRAM étaient d'origine nosocomiale et 19,5\%, d'origine non nosocomiale) et les ERV, $1,8 \%$ de tous les entérocoques ( $62,5 \%$ des ERV possédaient le génotype vanA). L'E coli producteur de BLLS s'observait dans 3,4 \% des isolats d'E coli. Le type CTX-M était le BLLS prédominant, et le CTX-M-15, le génotype prédominant. Pour ce qui est du SRAM, on n'a pas observé de résistance à la daptomycine, au limézolide, à la tygécycline et à la vancomycine, tandis que le taux de résistance aux autres agents s'établissait comme suit: clarithromycine $91,4 \%$, clindamycine $61,8 \%$, fluoroquinolones $88,6 \%$ à $89,6 \%$, et triméthoprim-sulfaméthoxazole $12,2 \%$. L'E coli n'était pas résistant à l'ertapénem, au méropénem et à la tigécycline, tandis que le taux de résistance aux autres agents s'établissait comme suit : amikacine $0,1 \%$, céfazoline 14,2\%, céfépime 2,0\%, ceftriaxone 8,9\%, gentamicine 10,6\%, fluoroquinolones $23,6 \%$ à $24,5 \%$, pipéracilline-tazobactam $1,3 \%$ et triméthoprim-sulfaméthoxazole $26,6 \%$. Le taux de résistance au $P$ aeruginosa se déclinait comme suit : amikacine 7,6\%, céfépime $11,7 \%$, gentamicine $20,8 \%$, fluoroquinolones $23,4 \%$ à $25,1 \%$, méropénem $8,1 \%$ et pipéracilline-tazobactam 7,3\%. Un phénotype multirésistant (à trois médicaments ou plus parmi la céfépime, la pipéracilline-tazobactam, le méropénem, l'amikacine ou la gentamicine et la ciprofloxacine) se produisait souvent dans les cas de $P$ aeruginosa $(10,6 \%)$, mais rarement dans ceux d'E coli (1,2\%), de K pneumoniae (1,5\%) d'E cloacae (0\%) ou de $\mathrm{H}$ influenzae $(0 \%)$.

CONCLUSIONS : L'E coli, le staphylocoque doré (susceptible à la méthicilline et le SARM), le $S$ pneumoniae, le $P$ aeruginosa, le $\mathrm{K}$ pneumoniae, le $\mathrm{H}$ influenzae et les espèces d'entérocoques sont les principaux isolats prélevés dans les échantillons cliniques d'hôpitaux canadiens. La prévalence du SARM y était de 26,0 \% (qui, du point de vue du génotype, s'associait à un SARM non nosocomial dans $19,5 \%$ des cas), tandis que les ERV et l'E coli producteur de BLLS s'observaient dans $1,8 \%$ et $3,4 \%$ des isolats, respectivement. Un phénotype multirésistant est courant en cas de $P$ aeruginosa dans les hôpitaux canadiens.
Tnfections caused by antimicrobial-resistant bacteria are rising 1 in Canada and the United States, which underscores the need for continued surveillance, appropriate antimicrobial prescribing, prudent infection control and new treatment alternatives (1-3). Commonly described antimicrobial-resistant pathogens including methicillin-resistant Staphylococcus aureus (MRSA; community-associated [CA-MRSA] and health care-associated [HA-MRSA]), vancomycin-resistant Enterococcus species (VRE), penicillin-resistant Streptococcus pneumoniae, extendedspectrum beta-lactamase (ESBL)-producing Escherichia coli and Klebsiella species, and fluoroquinolone-resistant and carbapenemresistant Enterobacteriaceae and Pseudomonas aeruginosa are increasing in prevalence in all regions of Canada, the United States and globally (4-11). Frequently, these antibiotic-resistant organisms display a multidrug-resistant (MDR) phenotype, which further limits treatment options $(2,4,11)$.

The purpose of the Canadian Ward Surveillance Study (CANWARD 2007) was to assess the prevalence of pathogens, including the resistance genotypes of MRSA, VRE and ESBL, causing infections in Canadian hospitals, as well as their antimicrobial resistance patterns. The present report is the first national, prospective surveillance study assessing antimicrobial resistance in Canadian hospitals.

\section{METHODS}

\section{Bacterial isolates}

The CANWARD 2007 study included 12 medical centres from all regions of Canada (www.can-r.ca). From January 1, 2007, to December 31, 2007, inclusive, each centre collected and submitted clinical isolates from patients attending hospital clinics, emergency rooms (ERs), medical and surgical wards, and intensive care units (ICUs). Each centre was asked to submit clinical isolates (consecutive, one organism/infection site per patient) from blood (360 isolates collected as 30 consecutive/month for each of the 12 months), respiratory $(n=200)$, urine $(n=100)$ and wound/intravenous $(n=50)$ infections. All organisms were identified at the originating centre using local site criteria and were deemed clinically significant. In total, 7881 isolates were collected. Isolates were shipped to the coordinating laboratory (Health Sciences Centre, Winnipeg, Manitoba) on Amies charcoal swabs, subcultured onto appropriate media, and stocked in skim milk at $-80^{\circ} \mathrm{C}$ until minimum inhibitory concentration (MIC) testing was carried out.

\section{Antimicrobial susceptibilities}

Susceptibility testing was carried out using microbroth dilution in accordance with the Clinical and Laboratory Standards Institute (CLSI) guidelines $(3,11,12)$. For all antimicrobials tested, MIC interpretive standards were defined according to 2006 CLSI breakpoints. Susceptibility testing could not be performed with all agents due to lack of space on the susceptibility panels. Thus, susceptibility testing was not performed with $P$ aeruginosa for ceftazidime, tobramycin and imipenem. The following interpretive breakpoints (Food and Drug Administration, USA) were used for tigecycline-susceptible (S), -intermediate (I) and -resistant (R): S aureus (methicillinsusceptible [MSSA] and MRSA) $0.5 \mu \mathrm{g} / \mathrm{mL}$ or less (S); Enterococcus faecalis (vancomycin-susceptible), $0.25 \mu \mathrm{g} / \mathrm{mL}$ or less (S); Enterobacteriaceae, $2 \mu \mathrm{g} / \mathrm{mL}$ or less (S), $4 \mu \mathrm{g} / \mathrm{mL}$ (I), and $8 \mu \mathrm{g} / \mathrm{mL}$ or higher $(\mathrm{R})$.

\section{Characterization of MRSA, ESBL-producing E coli and VRE}

MRSA: Potential MRSA isolates were confirmed using the CLSI disk diffusion method and mecA polymerase chain reaction (PCR). All isolates of MRSA were tested for PantonValentine leukocidin and typed using pulsed-field gel electrophoresis (PFGE) following the Canadian standardized protocol to assess whether the isolates were CA-MRSA or HA-MRSA (13-16). PFGE fingerprints were analyzed with BioNumerics version 3.5 (Applied Maths, USA) using a position tolerance of 1.0 and an optimization of 1.0. Strain relatedness was determined as previously described (17). Fingerprints were compared with the national MRSA fingerprint database and were grouped into one of 10 Canadian epidemic MRSA (CMRSA-1 to CMRSA-10) as previously described (15). In the present study, CA-MRSA and HA-MRSA were defined genotypically and not epidemiologically. Any MRSA with a CMRSA-7 (USA400/MW2) or CMRSA-10 (USA300) genotype was labelled as CA-MRSA, while all other genotypes (eg, CMRSA-1 [USA600], CMRSA-2 [USA100], CMRSA-4 [USA200]) were labelled as HA-MRSA. 
ESBL testing: Any E coli or Klebsiella species with a ceftriaxone MIC of $1 \mu \mathrm{g} / \mathrm{mL}$ or greater was identified as a potential ESBL producer as specified by CLSI. ESBL producers were confirmed using the CLSI double disk diffusion method and retested for MIC to both ceftriaxone and ceftazidime (18). PCR and DNA sequence analysis was used to identify bla $a_{\mathrm{SHV}}$, $b l a_{\text {TEM }}$ and bla $a_{\text {CTX-M }}$ genes among isolates, as previously described $(7,8,18)$.

VRE: Potential VRE isolates were confirmed using CLSI vancomycin disk diffusion testing and underwent van $\mathrm{A}$ and van B PCR as well as DNA fingerprinting to assess genetic similarity, as previously described $(10,19)$.

\section{RESULTS}

\section{Patient demographics and specimen types}

A total of 7881 isolates recovered from clinical specimens were collected from hospitals across Canada; $54.7 \%$ (4311 of 7881) of isolates were collected from males while 45.3\% (3570 of 7881) were from females. Patient age breakdown was: 17 years or younger, $11.7 \%$ (926 of 7881); 18 to 64 years, $47.3 \%$ (3726 of 7881); and 65 years and older, $41.0 \%$ (3229 of 7881). Organisms were obtained from respiratory specimens $(29.3 \%$; 2306 of 7881$)$, blood $(46.1 \% ; 3631$ of 7881$)$, wounds/tissue $(7.8 \% ; 617$ of 7881$)$ and urine $(16.8 \% ; 1327$ of 7881$)$.

\section{Most common organisms isolated in Canadian hospitals}

Table 1 describes the 20 most common organisms isolated in hospitals across Canada. The most common Gram-positive cocci included MSSA, S pneumoniae, MRSA, coagulasenegative staphylococci/Staphylococcus epidermidis and Enterococcus species, which together represented $34.7 \%$ of all isolates. The most common Gram-negative bacilli included E coli, $P$ aeruginosa, Klebsiella pneumoniae, Haemophilus influenzae and Enterobacter cloacae, which together made up 41.8\% of all organisms from hospitals across Canada.

\section{Most common organisms isolated by specimen site}

Table 2 describes the 10 most common isolates recovered from clinical specimens from the four specimen sites, including respiratory, blood, wounds/tissue and the urinary tract. Within the respiratory tract, $S$ pneumoniae, MSSA and MRSA were the most common Gram-positive cocci, accounting for $42.4 \%$ of isolates. For Gram-negative bacilli, P aeruginosa, $\mathrm{H}$ influenzae, E coli, Moraxella catarrhalis, Stenotrophomonas maltophilia, K pneumoniae and Serratia marcescens represented $46.9 \%$ of isolates obtained. Among blood culture isolates, Gram-positive cocci, including MSSA, coagulase-negative staphylococci/ $S$ epidermidis, $S$ pneumoniae, MRSA and $E$ faecalis made up $35.8 \%$ of organisms isolated in Canadian hospitals. The most common Gram-negative bacilli isolated from blood included E coli, $K$ pneumoniae, $P$ aeruginosa and $E$ cloacae, which made up $35.7 \%$ of all isolates. For wounds/tissue, Gram-positive cocci, including MSSA, MRSA, Streptococcus pyogenes, coagulase-negative staphylococci/S epidermidis and Enterococcus species made up $58.7 \%$ of the total isolates. The most common Gram-negative bacilli isolated from wounds/tissue were $P$ aeruginosa, E coli, E cloacae and $\mathrm{K}$ pneumoniae, which made up $25.7 \%$ of all isolates. From the urinary tract the most commonly isolated organisms were Gram-negative bacilli, including E coli, K pneumoniae, Proteus mirabilis, $P$ aeruginosa, E cloacae
TABLE 1

The 20 most common organisms isolated from Canadian hospitals

\begin{tabular}{|c|c|c|c|}
\hline Ranking & Organism & Isolates, n & $\%$ of total \\
\hline 1 & Escherichia coli & 1701 & 21.6 \\
\hline 2 & MSSA & 1095 & 13.9 \\
\hline 3 & Streptococcus pneumoniae & 702 & 8.9 \\
\hline 4 & Pseudomonas aeruginosa & 633 & 8.0 \\
\hline 5 & Klebsiella pneumoniae & 455 & 5.8 \\
\hline 6 & MRSA & 385 & 4.9 \\
\hline 7 & Haemophilus influenzae & 342 & 4.3 \\
\hline 8 & CNS/Staphylococcus epidermidis & 317 & 4.0 \\
\hline 9 & Enterococcus spp & 237 & 3.0 \\
\hline 10 & Enterobacter cloacae & 166 & 2.1 \\
\hline 11 & Enterococcus faecalis & 161 & 2.0 \\
\hline 12 & Proteus mirabilis & 119 & 1.5 \\
\hline 13 & Streptococcus agalactiae & 116 & 1.5 \\
\hline 14 & Serratia marcescens & 108 & 1.4 \\
\hline 15 & Stenotrophomonas maltophilia & 107 & 1.4 \\
\hline 16 & Streptococcus pyogenes & 105 & 1.3 \\
\hline 17 & Candida albicans & 103 & 1.3 \\
\hline 18 & Klebsiella oxytoca & 100 & 1.3 \\
\hline 19 & Moraxella catarrhalis & 93 & 1.2 \\
\hline \multirow[t]{2}{*}{20} & Streptococcus viridans & 66 & 0.8 \\
\hline & Other* & 770 & 9.8 \\
\hline Total & & 7881 & 100.0 \\
\hline
\end{tabular}

${ }^{*}$ Other: Achromobacter species (spp), Acinetobacter spp, Aeromonas spp, Bacillus spp, Burkholderia spp, Candida spp, Chryseobacterium spp, Citrobacter spp, Corynebacterium spp, Dermabacter spp, Enterobacter spp, Enterococcus spp, Flavobacterium spp, Gemella spp, Gordonia spp, Haemophilus spp, Klebsiella spp, Kluyvera spp, Kocuria spp, Listeria spp, Micrococcus spp, Morganella spp, Neisseria spp, Pantoea spp, Proteus spp, Providencia spp, Pseudomonas spp, Raoultella spp, Rhodococcus spp, Roseomonas spp, Salmonella $s p p$, Sphingobacterium spp, Serratia $s p p$, Staphylococcus spp, Stomatococcus spp, Streptococcus spp, Yersinia spp. CNS Coagulase-negative staphylococci; MRSA Methicillin-resistant Staphylococcus aureus; MSSA Methicillin-susceptible S aureus

and Klebsiella oxytoca, which made up $74.7 \%$ of isolates. Gram-positive cocci obtained from the urinary tract most commonly included Enterococcus species, coagulase-negative staphylococci/S epidermidis, Streptococcus agalactiae and MSSA, which made up $19.0 \%$ of isolates.

\section{Characteristics of MRSA}

Of the 385 MRSA (26.0\% of all S aureus) isolated from hospitals in Canada, $19.5 \%$ were CA-MRSA and $79.2 \%$ were HA-MRSA, as determined by PFGE; $1.3 \%$ of MRSA could not be genotypically classified. CA-MRSA belonged to PFGE types CMRSA10/USA300 (66.7\%) and CMRSA7/USA400 (33.3\%); PFGE types identified among HA-MRSA included CMRSA2/USA100/800 (81.6\%), CMRSA6 (13.1\%), CMRSA1/USA600 (3.3\%), CMRSA5/USA500 (1.3\%), CMRSA3 $(0.3 \%)$ and CMRSA9 (0.3\%). Panton-Valentine leukocidin was detected in $94.7 \%$ of CA-MRSA and $0.7 \%$ of HA-MRSA. More data on MRSA in CANWARD 2007 are described by Nichol et al (20) in the present supplement.

\section{Characteristics of ESBL E coli}

Fifty-three of 1560 (3.4\%) E coli were ESBL producers. ESBLproducing E coli ranged from 1.1\% in ERs, $1.9 \%$ in ICUs, 3.3\% 


\section{TABLE 2}

The 10 most common organisms isolated by specimen site in Canadian hospitals

\begin{tabular}{|c|c|c|c|}
\hline Ranking & Organism & Isolates, n & $\%$ of total \\
\hline \multicolumn{4}{|c|}{ Respiratory ( $\mathrm{n}=\mathbf{2 3 0 6}$ or $\mathbf{2 9 . 3 \% )}$} \\
\hline 1 & Streptococcus pneumoniae & 471 & 20.4 \\
\hline 2 & MSSA & 383 & 16.6 \\
\hline 3 & Pseudomonas aeruginosa & 380 & 16.5 \\
\hline 4 & Haemophilus influenzae & 321 & 13.9 \\
\hline 5 & MRSA & 125 & 5.4 \\
\hline 6 & Escherichia coli & 102 & 4.4 \\
\hline 7 & Moraxella catarrhalis & 91 & 3.9 \\
\hline 8 & Stenotrophomonas maltophilia & 79 & 3.4 \\
\hline 9 & Klebsiella pneumoniae & 61 & 2.6 \\
\hline \multirow[t]{2}{*}{10} & Serratia marcescens & 51 & 2.2 \\
\hline & Other & 242 & 10.7 \\
\hline Total & & 2292 & 100.0 \\
\hline \multicolumn{4}{|c|}{ Blood ( $n=3631$ or $46.1 \%)$} \\
\hline 1 & E coli & 797 & 21.9 \\
\hline 2 & MSSA & 485 & 13.4 \\
\hline 3 & $K$ pneumoniae & 266 & 7.3 \\
\hline 4 & CNS/Staphylococcus epidermidis & 257 & 7.1 \\
\hline 5 & S pneumoniae & 232 & 6.4 \\
\hline 6 & MRSA & 172 & 4.7 \\
\hline 7 & Enterococcus faecalis & 154 & 4.2 \\
\hline 8 & $P$ aeruginosa & 148 & 4.1 \\
\hline 9 & Candida albicans & 103 & 2.8 \\
\hline \multirow[t]{2}{*}{10} & Enterobacter cloacae & 88 & 2.4 \\
\hline & Other & 929 & 25.7 \\
\hline Total & & 3631 & 100.0 \\
\hline \multicolumn{4}{|c|}{ Wounds/Tissue ( $n=617$ or $7.8 \%)$} \\
\hline 1 & MSSA & 203 & 32.9 \\
\hline 2 & MRSA & 77 & 12.5 \\
\hline 3 & $P$ aeruginosa & 63 & 10.2 \\
\hline 4 & E coli & 57 & 9.2 \\
\hline 5 & Streptococcus pyogenes & 31 & 5.0 \\
\hline 6 & CNS/S epidermidis & 26 & 4.2 \\
\hline 7 & Enterococcus species & 25 & 4.1 \\
\hline 8 & E cloacae & 21 & 3.4 \\
\hline 9 & Streptococcus agalactiae & 20 & 3.2 \\
\hline \multirow[t]{2}{*}{10} & K pneumoniae & 18 & 2.9 \\
\hline & Other & 76 & 12.4 \\
\hline Total & & 581 & 100.0 \\
\hline \multicolumn{4}{|c|}{ Urine $(n=1327$ or $16.8 \%)$} \\
\hline 1 & E coli & 751 & 56.6 \\
\hline 2 & Enterococcus species & 175 & 13.2 \\
\hline 3 & K pneumoniae & 112 & 8.4 \\
\hline 4 & Proteus mirabilis & 49 & 3.7 \\
\hline 5 & $P$ aeruginosa & 43 & 3.2 \\
\hline 6 & CNS/S epidermidis & 29 & 2.2 \\
\hline 7 & S agalactiae & 27 & 2.0 \\
\hline 8 & MSSA & 21 & 1.6 \\
\hline 9 & E cloacae & 19 & 1.4 \\
\hline \multirow[t]{2}{*}{10} & Klebsiella oxytoca & 19 & 1.4 \\
\hline & Other & 82 & 6.3 \\
\hline Total & & 1327 & 100.0 \\
\hline
\end{tabular}

CNS Coagulase-negative staphylococci; MRSA Methicillin-resistant Staphylococcus aureus; MSSA Methicillin-susceptible S aureus

in hospital clinics, $6.2 \%$ in medical wards and $7.9 \%$ in surgical wards. ESBL-producing E coli were identified from 11 of the 12 sites, and the prevalence ranged from $0 \%$ to $9.3 \%$ among participating hospitals. Of the 53 ESBL-producing E coli, 51
(96.2\%) were of the CTX-M genotype with 28 (52.8\%) $b l a_{\text {CTX-M-15 }}, 17$ (32.1\%) bla $a_{\text {CTX-M-14 }}$, two $(3.8 \%) b l a_{\text {CTX-M-27 }}$ and one $(1.9 \%)$ each of bla ${ }_{\text {CTX-M-3. }}, b l a_{\text {CTX-M-24, }}, b_{\text {CTX-M-65, }}$, bla $_{\mathrm{SHV} 2 \mathrm{a}}$ and an unknown. More data on ESBL-producing E coli in CANWARD 2007 are described by Baudry et al (21) in the present supplement.

\section{Characteristics of VRE}

Of the 1.8\% VRE (eight of 450 of all Enterococci species) isolated, $62.5 \%$ displayed a vanA genotype, while $37.5 \%$ displayed a van B genotype. All VRE were E faecium.

\section{Antimicrobial susceptibility}

Antimicrobial resistance rates (per cent of isolates determined to be intermediate and resistant) for the most common Grampositive cocci based on specimen source are listed in Table 3 . With MRSA, no resistance was observed to daptomycin, linezolid, tigecycline and vancomycin. Nitrofurantoin (urinary indication only) proved to be active against MRSA as well, with $0 \%$ resistance (Table 3). Resistance rates with MRSA were: clarithromycin $91.4 \%$, clindamycin $61.8 \%$, fluoroquinolones $88.6 \%$ to $89.6 \%$, and trimethoprim-sulfamethoxazole (SXT) $12.2 \%$ (Table 3). The lowest rates of resistance with MRSA occurred in wound specimens with clindamycin and SXT (Table 3). With methicillin-resistant $S$ epidermidis (MRSE), no resistance was observed to daptomycin, linezolid and vancomycin. No Food and Drug Administration (USA) breakpoints are available for tigecycline and MRSE, but when MRSA breakpoints were applied, MRSE resistance was 0\% with tigecycline. Resistance rates with MRSE were: clarithromycin $90.0 \%$, clindamycin $90.0 \%$, fluoroquinolones $95.0 \%$ to $100 \%$, and SXT $75.0 \%$ (Table 3). With S pneumoniae, no resistance was observed to vancomycin or linezolid. Resistance rates with S pneumoniae were: fluoroquinolones $0.6 \%$ to $4.3 \%$, ceftriaxone $0.1 \%$, carbapenems $0.1 \%$ to $0.3 \%$, clarithromycin $12.9 \%$, clindamycin $5.7 \%$ and SXT $7.0 \%$ (Table 3). Resistance rates for all agents tested were higher in $S$ pneumoniae obtained from respiratory versus blood specimens (Table 3). With E faecalis, no resistance was observed to vancomycin, daptomycin and tigecycline (using $E$ faecalis breakpoints). Resistance rates with $E$ faecalis were: fluoroquinolones $31.8 \%$ to $35.1 \%$, linezolid $1.3 \%$ (intermediate resistance only) and nitrofurantoin (urinary indication only) $1.2 \%$ (intermediate resistance only) (Table 3). Higher resistance for tested agents was observed with $E$ faecium compared with $E$ faecalis including vancomycin, with resistance of $12.0 \%$ (Table 3).

Antimicrobial resistance rates (per cent of isolates determined to be intermediate and resistant) for the most common Gram-positive cocci based on hospital ward location are listed in Table 4. With S aureus (MSSA), resistance rates for fluoroquinolones, clarithromycin, clindamycin and SXT were not influenced by ward location, with similar rates in hospital clinics, ERs, ICUs, and medical and surgical wards (Table 4). Resistance rates with MRSA obtained from the ER were lower versus other hospital areas for fluoroquinolones, clindamycin and SXT (Table 4). With S pneumoniae, limited differences occurred with beta-lactams, fluoroquinolones and SXT per hospital ward location, likely due to low resistance rates overall for these agents. S pneumoniae resistance with clarithromycin and clindamycin occurred in all hospitals areas (Table 4). 


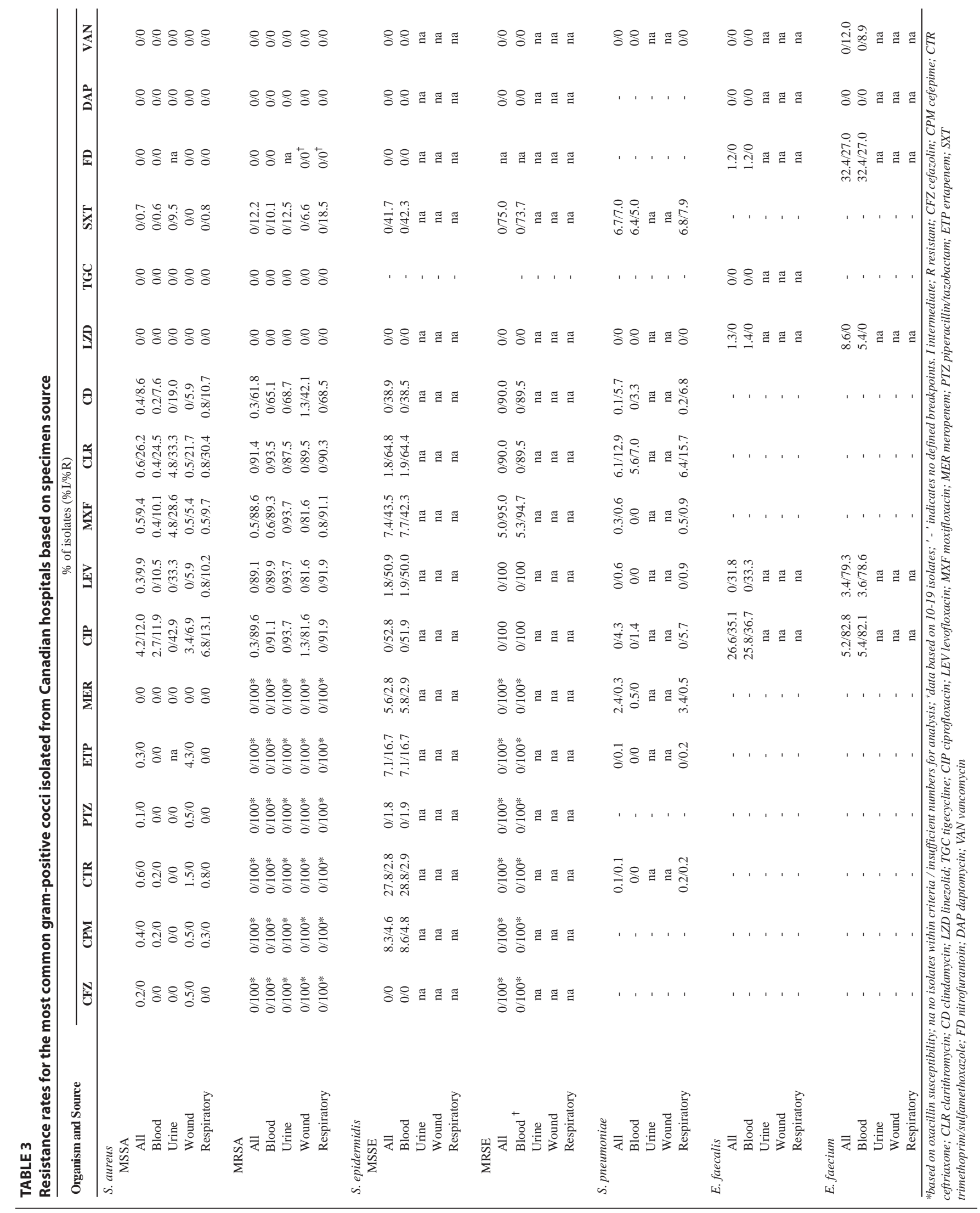

E faecalis and E faecium resistance occurred in all hospital areas (Table 4).

Antimicrobial resistance rates (per cent of isolates determined to be intermediate and resistant) for the most common
Gram-negative bacilli based on specimen source are listed in Table 5. With E coli, no resistance was observed to ertapenem, meropenem and tigecycline (Table 5). Resistance rates with E coli were: amoxicillin-clavulanate $1.2 \%$, cefazolin $14.2 \%$, 


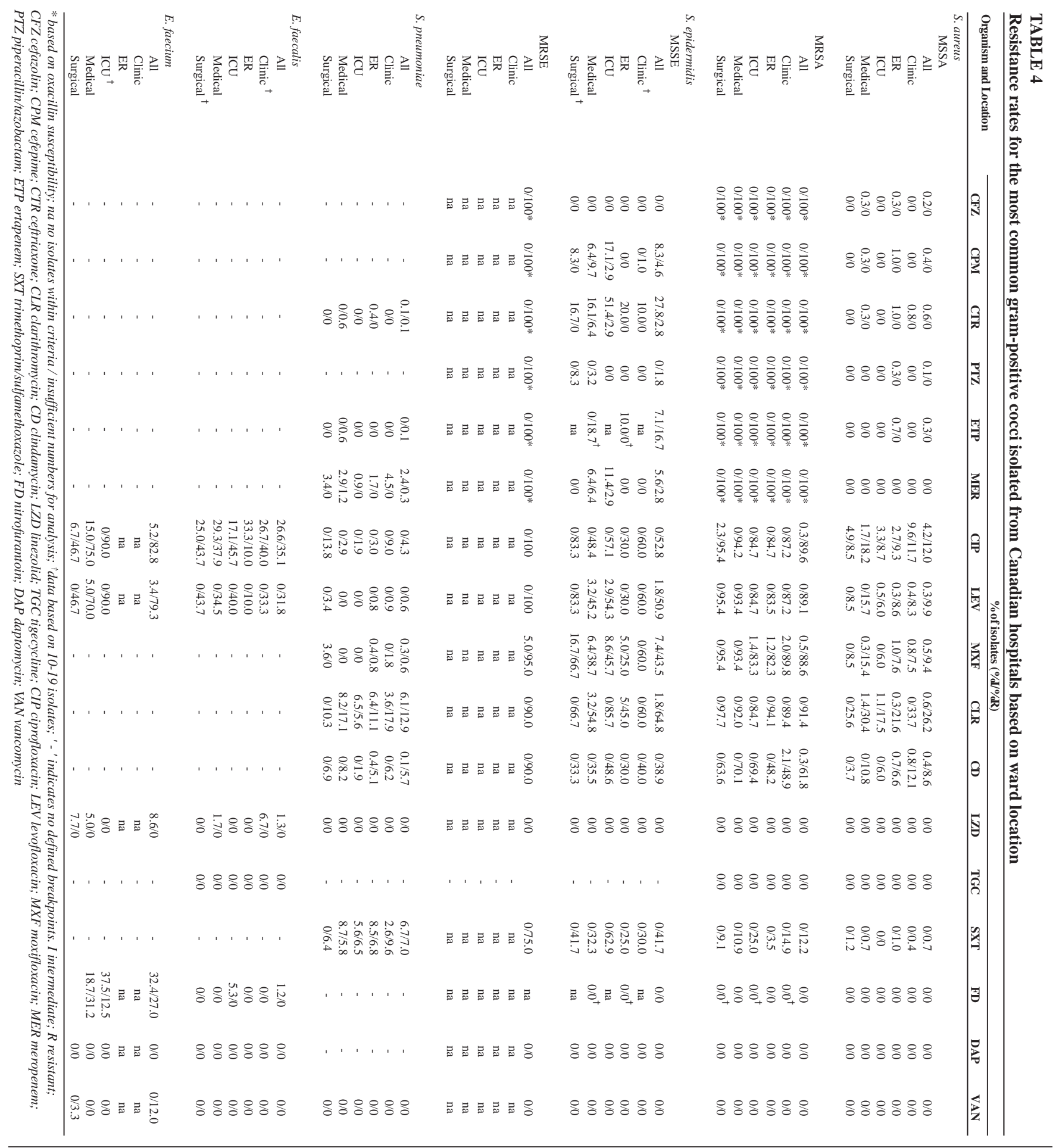

cefepime $2.0 \%$, ceftriaxone $8.9 \%$, gentamicin $10.6 \%$, fluoroquinolones $23.6 \%$ to $24.5 \%$, piperacillin-tazobactam $1.3 \%$ and SXT 26.6\% (Table 5). Resistance rates for beta-lactams and E coli was highest in isolates obtained from wound specimens (Table 5). Resistance rates with $P$ aeruginosa were: amikacin $7.6 \%$, cefepime $11.7 \%$, gentamicin $20.8 \%$, fluoroquinolones $23.4 \%$ to $25.1 \%$, meropenem $8.1 \%$, piperacillin-tazobactam $7.3 \%$ and colistin (polymyxin E) 2.2\% (Table 5). Resistance rates with aminoglycosides were highest in $P$ aeruginosa obtained from respiratory specimens and highest with fluoroquinolones in urinary and respiratory $P$ aeruginosa (Table 5). With K pneumoniae, no resistance was observed to ertapenem and meropenem (Table 5). Resistance rates with $K$ pneumoniae were: cefazolin $6.8 \%$, ceftriaxone $3.1 \%$, cefepime $2.2 \%$, fluoroquinolones $4.2 \%$ to $6.6 \%$, amikacin $0.4 \%$, gentamicin $2.9 \%$, piperacillin-tazobactam $2.0 \%$, tigecycline $1.5 \%$ and SXT $8.6 \%$.

Antimicrobial resistance rates (per cent of isolates determined to be intermediate and resistant) for the most common Gram-negative bacilli based on hospital ward location are 


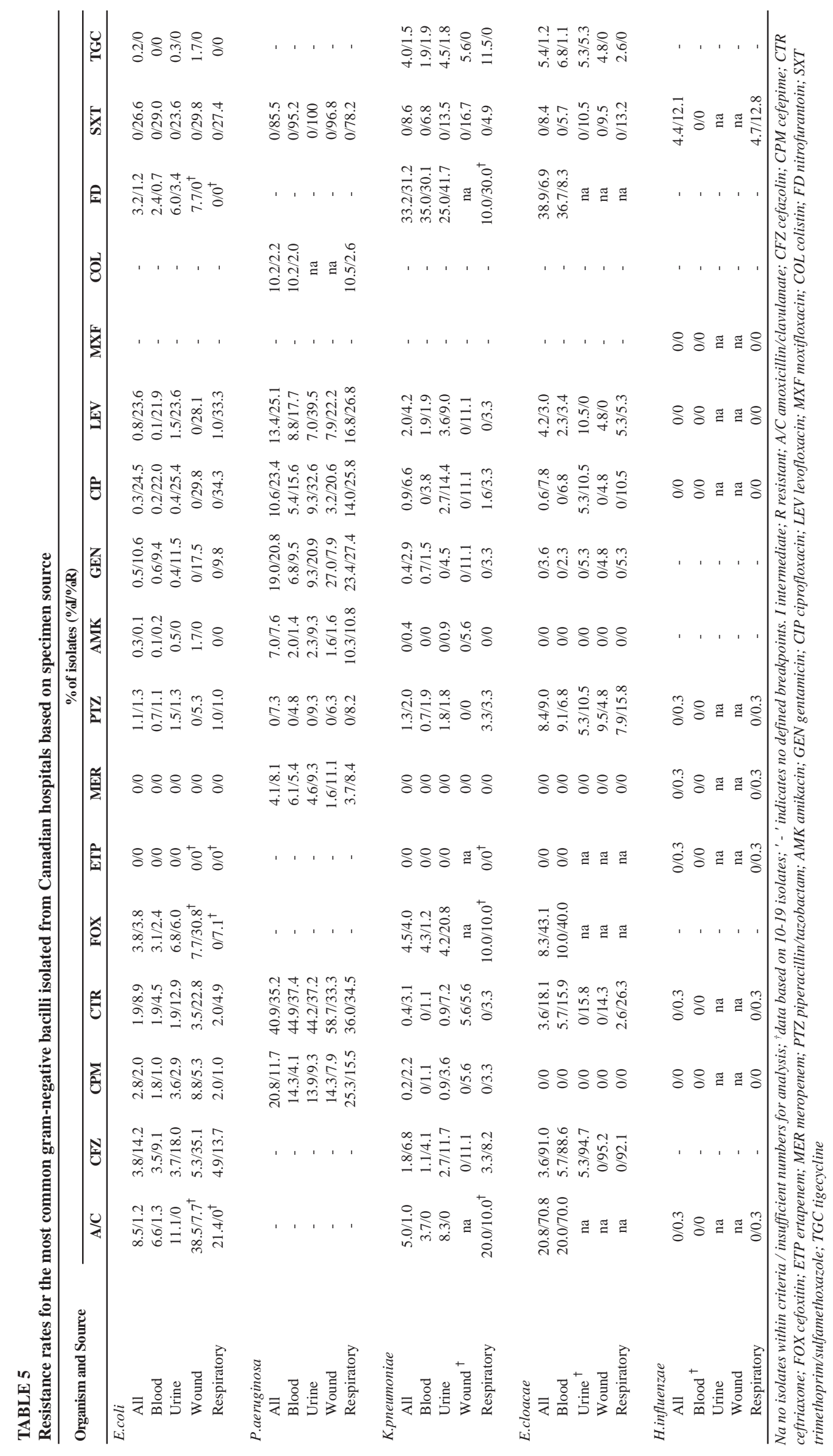




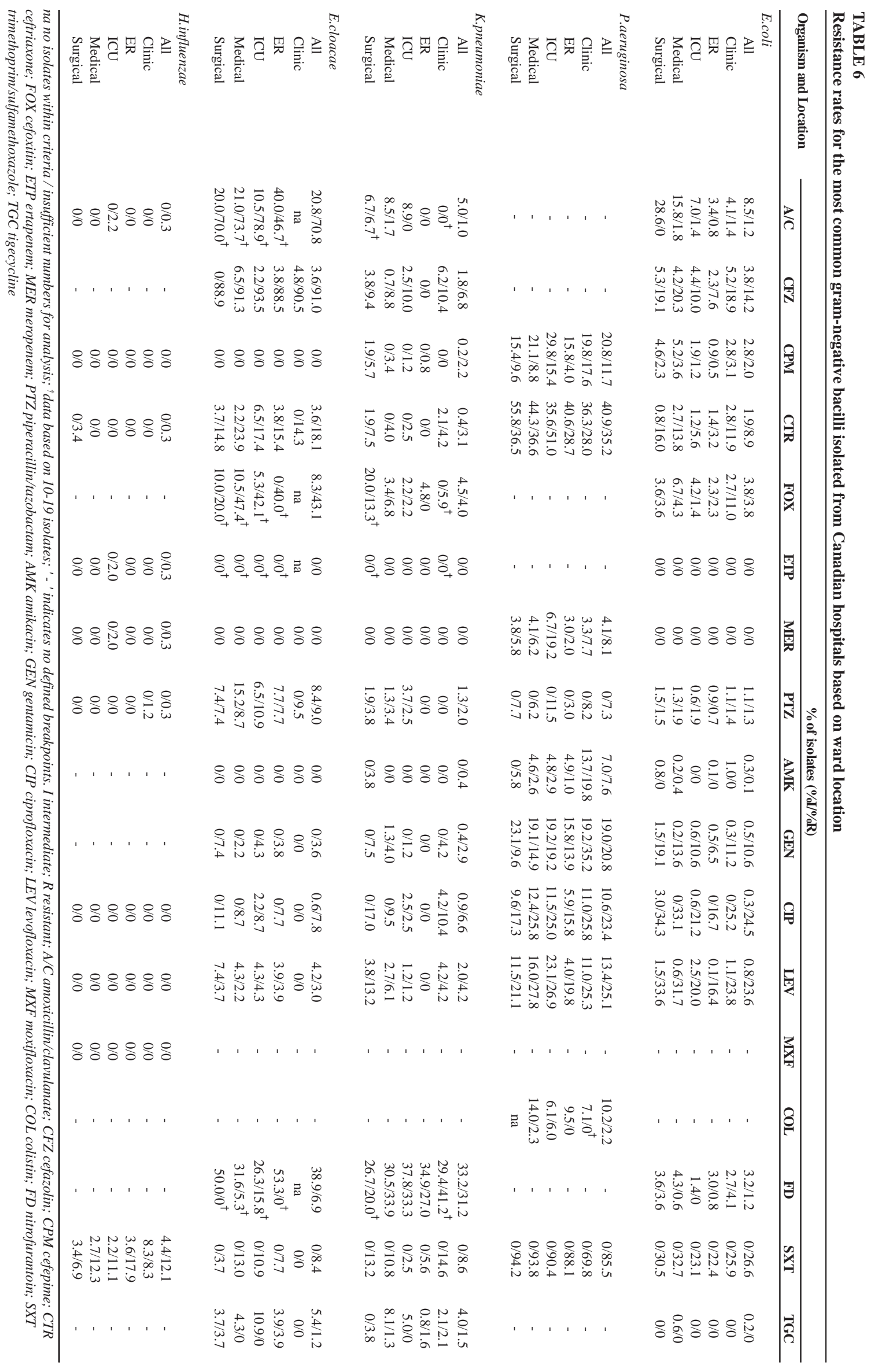


listed in Table 6. With E coli and K pneumoniae, resistance rates for penicillins, cephalosporins, fluoroquinolones, aminoglycosides and SXT were highest from medical and surgical ward specimens and lowest in ER specimens (Table 6). With P aeruginosa, resistance rates were highest in ICU specimens for penicillins, cephalosporins, carbapenems, fluoroquinolones and colistin (Table 6). Aminoglycoside resistance with $P$ aeruginosa was highest in hospital clinics, which included cystic fibrosis clinics (Table 6).

\section{MDR}

MDR was assessed in Gram-negative organisms only, because no accepted definition exists for Gram-positive organisms (Table 7). MDR for Gram-negative organisms was defined as resistance to three or more of the following: cefepime, piperacillin-tazobactam, meropenem, amikacin or gentamicin, and ciprofloxacin (adapted from reference 1). The MDR phenotype was most common in $P$ aeruginosa at $10.6 \%$. A MDR phenotype occurred in $1.2 \%$ of E coli, $1.5 \%$ of $K$ pneumoniae, and $0 \%$ of $E$ cloacae and $H$ influenzae (Table 7).

\section{DISCUSSION}

The CANWARD study was the first national, prospective surveillance study assessing antimicrobial resistance in hospitals across Canada. This national surveillance study involving 12 medical centres in major population centres in seven of the 10 provinces in Canada collected isolates from blood, respiratory, wound and urinary specimens. Unlike previous studies that documented that more than one-half of all isolates recovered from clinical specimens in hospitals were from the respiratory tract, the CANWARD study could not make such a conclusion because it was set up to collect isolates from a variety of specimen sources to assess antimicrobial resistance patterns, rather than assessing the prevalence of infectious diseases in Canadian hospitals $(1,3)$. It has previously been reported that of the deaths associated with heath care-associated infections in American hospitals (National Nosocomial Infections Surveillance [NNIS], 2002), approximately 36.3\% were respiratory, $31.0 \%$ were bloodstream, $13.2 \%$ were urinary tract and $8.3 \%$ were surgical site (wound) infections (22). We report that the 10 most common isolates recovered from $76.5 \%$ of all clinical specimens in hospitals across Canada were $E$ coli, MSSA, $S$ pneumoniae, $P$ aeruginosa, $K$ pneumoniae, MRSA, $H$ influenzae, coagulase-negative staphylococci/S epidermidis, Enterococcus species and E cloacae (Table 1). Our data are in keeping with previous reports that Gram-positive cocci including MSSA, S pneumoniae, MRSA and Enterococcus species are the most common Gram-positive isolates recovered from clinical specimens in North American hospitals $(3,23)$. The recent report by Lockhart et al (1) that the most common Gramnegative bacilli isolated from American institutions from 1993 to 2004 were $P$ aeruginosa, E coli, K pneumoniae and E cloacae is also consistent with our findings.

In all hospitals involved in the CANWARD study, MSSA and MRSA were important isolates recovered from clinical specimens including bacteremia, respiratory tract specimens and wound/tissue specimens. MRSA made up 26.0\% of all staphylococci and, surprisingly, $19.5 \%$ of all MRSA in Canadian hospitals were CA-MRSA. In a previous study involving

\section{TABLE 7}

Multidrug-resistant (MDR) phenotypes in Canadian hospitals

\begin{tabular}{lcc}
\hline Organism & Total isolates, $\mathbf{n}$ & MDR isolates, $\mathbf{n}(\%)$ \\
\hline Escherichia coli & 1701 & $21(1.2)$ \\
Pseudomonas aeruginosa & 633 & $67(10.6)$ \\
Klebsiella pneumoniae & 455 & $7(1.5)$ \\
Enterobacter cloacae & 166 & $0(0)$ \\
Haemophilus influenzae & 329 & $0(0)$ \\
\hline
\end{tabular}

MDR for Gram-negative bacilli defined as resistant to three or more of the following: cefepime, piperacillin/tazobactam, meropenem, amikacin or gentamicin, and ciprofloxacin

19 ICUs across Canada (3), we reported that 9.1\% of all MRSA were CA-MRSA. Thus, it is clear that CA-MRSA genotypes are rapidly spreading across Canadian hospitals. The most common CA-MRSA genotypes continue to be CMRSA10/ USA300 (66.7\%) and CMRSA7/USA400 (33.3\%), which is consistent with previous reports $(4,11,13,15)$. The most common HA-MRSA genotypes in Canadian hospitals were CMRSA2/USA100/800 (81.6\%) and CMRSA6 (13.1\%), which has also been previously documented $(4,11,13,15)$. The CANWARD study also showed that VRE made up only $1.8 \%$ of all enterococci with the vanA genotype (mostly E faecium) making up $62.5 \%$ of all VRE. The present study, as well as previous work, confirms that $E$ faecium carrying vanA is the predominant genotype in North America $(10,11,19)$. The low level of VRE across Canada has been previously documented and shows the lack of spread of VRE across the country $(10,11)$. Whether the low level of VRE in Canadian hospitals reflects the use of active surveillance programs, which have been reported to prevent VRE colonization and bacteremia, is unknown (24,25). A recent Australian study has reported that aggressive hand hygiene does not only reduce the incidence of MRSA infections but can also lower MRSA bacteremia (26).

The CANWARD study found that $3.4 \%$ of $E$ coli were ESBL producers. Most concerning was that ESBL-producing E coli were isolated from all hospital areas (ie, ERs, ICUs, hospital clinics, and medical and surgical wards). In addition, because ESBL-producing $E$ coli were identified in 11 of the 12 sites, and because $90.6 \%$ of the isolates displayed an MDR phenotype, it is strongly suspected that MDR ESBL-producing E coli are now firmly established in Canadian hospitals. This study showed that the CTX-M genotype (bla $a_{\text {CTX-M-15 }}$ and bla $a_{\text {CTX-M-14 }}$ ) was the predominant genotype in Canadian hospitals. Other studies assessing ESBL-producing E coli have shown that the CTX-M genotype is spreading rapidly in both community and hospital settings $(5,7,8,11,18,27,28)$. Pitout et al (8) investigated the molecular epidemiology of ESBLproducing E coli collected from 2000 to 2005, inclusive, in the Calgary Health Region. These investigators reported that $64 \%$ (354 of 552) of ESBL-producing E coli were PCR-positive for bla $_{\text {CTX-M }}$ genes, with CTX-M-14 (59.6\%) and CTX-M-15 $(36.2 \%)$ reported most commonly. Our study highlights the rapid spread of MDR ESBL CTX-M-15 E coli in Canadian hospitals. This MDR phenotype may be spreading rapidly due to the extensive use of third-generation cephalosporins and fluoroquinolones.

The present study showed that with the exception of MRSA, where resistance to fluoroquinolones, clindamycin and 
SXT was lower in the ER compared with other hospital locations, little differences in resistance rates with Gram-positive cocci were observed among various hospital locations. This is consistent with previous studies where higher resistance rates in the ICU as well as medical and surgical wards have been reported with Gram-negative bacilli but not Gram-positive cocci $(1,3,29,30)$. In agreement with previous studies, we found that resistance rates with $E$ coli and $K$ pneumoniae were highest from medical and surgical ward specimens and lowest in ER specimens, whereas with $P$ aeruginosa, resistance rates were highest in the $\operatorname{ICU}(1,3,30)$. The reason that resistance rates were high in clinics is because these primarily represented hospital specialty clinics such as cystic fibrosis clinics rather than acute care outpatient clinics.

With MRSA, resistance rates were very high with fluoroquinolones, macrolides (such as clarithromycin) and clindamycin, but lower with SXT (12.2\%). These resistance rates are consistent with previous reports $(3,15)$. Thus, SXT still represents a reasonable empirical treatment for mild to moderate infections (eg, skin and soft tissue infections) caused by CA-MRSA or HA-MRSA. All MRSA were susceptible to vancomycin, linezolid, tigecycline and daptomycin. It should be stated that even though only four of 385 (1.0\%) MRSA demonstrated vancomycin MICs of $2 \mu \mathrm{g} / \mathrm{mL}$, unlike others, we did not assess the prevalence of heteroresistant vancomycinintermediate $S$ aureus by population analysis profiling (31). A recent analysis from Detroit identified 8.3\% (of 917 strains assessed from 2003 to 2007) of MRSA as heteroresistant vancomycin-intermediate $S$ aureus (31). All MRSE were susceptible to vancomycin, linezolid, tigecycline and daptomycin, while no Enterococcus species proved to be resistant to tigecycline or daptomycin. The lowest rates of resistance for Gramnegative bacilli occurred with amikacin, cefepime, ertapenem (except $P$ aeruginos $a$ ), meropenem and piperacillin-tazobactam, which is consistent with previous reports $(1,3,30)$. The low resistance with amikacin likely reflects the low usage of aminoglycosides in favour of the fluoroquinolones in Canada and the United States over the past decade. In contrast, fluoroquinolone resistance was high with E coli $(23.6 \%$ to $24.5 \%)$ and $P$ aeruginosa (23.4\% to $25.1 \%$ ), which is consistent with other reports $(1,3,30)$, and reflects extensive fluoroquinolone usage (27). A recent report documented increasing prevalence of MDR Gram-negative bacilli in American ICUs (1). Although our definition of MDR for Gram-negative bacilli (resistance to three or more of the following: cefepime, piperacillin-tazobactam, meropenem, amikacin or gentamicin, and ciprofloxacin), was slightly more restrictive, our MDR rates of $10.6 \%$ with $P$ aeruginosa were somewhat higher than previously reported in the United States, at 9.3\% (1). In contrast, MDR rates in Canadian hospitals of $1.2 \%$ with $E$ coli, $0 \%$ with E cloacae, and $1.5 \%$ with $K$ pneumoniae are lower than those in American institutions at $2.0 \%, 5.9 \%$ and $13.3 \%$, respectively. Why MDR rates are higher in Canada with $P$ aeruginosa and lower with Enterobacteriaceae ( $E$ coli, E cloacae and $K$ pneumoniae) is unclear, but may be due to the lower prevalence of ESBLproducing Enterobacteriaceae in Canada $(3,11)$. MDR ESBLproducing $E$ coli were all susceptible to the carbapenems, ertapenem and meropenem, as well as tigecycline.

The limitations of the CANWARD study are numerous, including the fact that we cannot be certain that all clinical specimens represented active infection. As in our previous CAN-ICU study $(3,11)$, we asked centres to obtain "clinically significant" specimens from patients with a presumed infectious disease. Although all of the isolates may not represent actual infection from patients, we believe that most do because we excluded all surveillance swabs, duplicate swabs, eye, ear, nose and throat swabs, and genital cultures. Another limitation is that we do not have admission date data for each patient and clinical specimen, thus were not able to provide a more accurate description of community versus nosocomial onset. In the present study, CA-MRSA and HA-MRSA were defined genotypically and not epidemiologically. Any MRSA with a CMRSA-7 (USA400/MW2) or CMRSA-10 (USA300) genotype were labelled as CA-MRSA while all other genotypes (eg, CMRSA-1 [USA600], CMRSA-2 [USA100], CMRSA-4 [USA200]) were labelled as HA-MRSA. It is known epidemiologically that CA-MRSA genotypes can be associated with health care-associated infections and that HA-MRSA can be associated with community-associated infections (13). E coli and K pneumoniae were screened for potential ESBL production using only ceftriaxone, which, although consistent with CLSI guidelines, may have missed some SHV-producing $\mathrm{K}$ pneumoniae strains by not also testing ceftazidime. Whether this accounted for the reduced number of ESBL-producing $K$ pneumoniae versus ESBL-producing E coli is unclear. Finally, susceptibility testing was not performed for all antimicrobial agents due to lack of space on the susceptibility panels utilized. It is recognized that data on antimicrobials such a ceftazidime, imipenem, tobramycin and others would be beneficial, because different hospital formularies stock these and other antimicrobials not tested in the present study.

\section{CONCLUSIONS}

E coli, $S$ aureus (MSSA and MRSA), S pneumoniae, $P$ aeruginosa, K pneumoniae, $H$ influenzae and Enterococcus species are the most common isolates recovered from clinical specimens in Canadian hospitals. The prevalence of MRSA was 26.0\% (of which genotypically, $19.5 \%$ was CA-MRSA), VRE $1.8 \%$ and ESBL-producing E coli 3.4\% of isolates. A MDR phenotype is common with $P$ aeruginosa in Canadian hospitals.

ACKNOWLEDGEMENTS: This paper was presented in part at the 48th Interscience Conference on Antimicrobial Agents and Chemotherapy-ICAAC (2008) in Washington, DC. Funding for the CANWARD 2007 study was provided in part by the University of Manitoba, Health Sciences Centre in Winnipeg, National Microbiology Laboratory-Health Canada, Abbott, Affinium Inc, Astellas, Bayer, Janssen Ortho Inc, Merck, Oryx, Pfizer Canada, TaiGen, Targanta and Wyeth Inc. Special thanks to Nancy Laing, Barb Weshnoweski, Ravi Vashisht, Franil Tailor, Lisa Bittner and Haley Butcher for technological assistance. The authors wish to thank M Tarka for expert secretarial assistance.

\section{APPENDIX 1}

The authors thank the investigators and laboratory site staff at each medical centre that participated in the CANWARD 2007 study: Vancouver Hospital, Vancouver, British Columbia - Dr D Roscoe; University of Alberta Hospitals, Edmonton, Alberta - Dr R Rennie; Royal University Hospital, Saskatoon, Saskatchewan - Dr J Blondeau; Health Sciences Centre, Winnipeg, Manitoba - Drs D Hoban/G Zhanel; Mount Sinai 
Hospital, Toronto, Ontario - Dr S Poutanen; Children's Hospital of Eastern Ontario, Ottawa, Ontario - Dr F Chan; London Health Sciences Centre, London, Ontario - Dr Z Hussain; St Joseph's Hospital, Hamilton, Ontario - Dr C Lee; Hopital Maisonneuve-Rosemont, Montreal, Quebec - Dr M Laverdiere; Montreal General Hospital, Montreal, Quebec Dr V Loo; Royal Victoria Hospital, Montreal, Quebec - Dr V Loo; QEII Health Sciences Centre, Halifax, Nova Scotia - Drs K Forward/R Davidson. CANWARD data are also displayed at www.can-r.ca, the official Web site of the Canadian Antimicrobial Resistance Alliance (CARA).

\section{REFERENCES}

1. Lockhart SR, Abramson MA, Beekman SE, et al. Antimicrobial resistance among gram-negative bacilli as causes of infections in intensive care unit patients in the United States between 1993. 2004. J Clin Microbiol 2007;45:3352-59.

2. Rubinstein E, Zhanel GG. Anti-infectives research and development problems challenges and solutions: The clinical practitioner perspective. Lancet Infect Dis 2007;7:69-70.

3. Zhanel GG, DeCorby M, Laing N, et al. Antimicrobial-resistant pathogens in intensive care units in Canada: Results of the Canadian National Intensive Care Unit (CAN-ICU) Study, 2005/2006. Antimicrob Agents Chemother 2008;52:1430-37.

4. Chambers HF. Community-associated MRSA-resistance and virulence converge. N Engl J Med 2005;352:1485-87.

5. Brasme L, Nordmann P, Fidel F, et al. Incidence of class A extended-spectrum $\beta$-lactamases in Champagne-Ardenne (France): a 1 year prospective study. J Antimicrob Chemother 2007;60:956-64.

6. Gilbert MJ, MacDonald D, Gregson J, et al. Outbreak in Alberta of community-acquired (USA300) methicillin-resistant $\backslash$ Staphylococcus aureus in people with a history of drug use, homelessness and incarceration. Can Med Assoc J 2006;175:149-54.

7. Pitout JD, Nordman DP, Laupland KB, et al. Emergence of Enterobacteriaceae producing extended-spectrum $\beta$-lactamases (ESBLs) in the community. J Antimicrob Chemother 2005;56:52-9.

8. Pitout JD, Church DL, Gregson DB, et al. Molecular epidemiology of CTX-M-producing Escherichia coli in the calgary health region: Emergence of CTX-M-15 producing isolates. Antimicrob Agents Chemother 2007;51:1281-86.

9. Shadel BN, Puzniak LA, Gillespie KN, et al. Surveillance for vancomycin-resistant enterococci: Type, rates costs and implications. Infect Cont Hosp Epid 2006;27:1068-75.

10. Zhanel GG, Laing NM, Nichol KA, et al. Antibiotic activity against urinary tract infection (UTI) isolates of vancomycinresistant enterococci (VRE): Results from the 2002 North America Vancomycin Resistant Enterococci Susceptibility Study (NAVRESS). J Antimicrob Chemother 2004;52:382-88.

11. Zhanel GG, DeCorby M, Nichol KA, et al. Characterization of MRSA, VRE and ESBL producing E. coli in Intensive Care Units in Canada: Results of the Canadian National Intensive Care Unit (CAN-ICU) Study, 2005/2006. Can J Infect Dis Med Microbiol 2008;19(3):243-49.

12. Clinical and Laboratory Standards Institute. Performance standards for antimicrobial susceptibility testing: 16th informational supplement document M100-S16. CLSI/NCCLS M100-S15. Clinical and Laboratory Standards Institute, Wayne, PA. 2006.

13. Christianson S, Golding GR, Campbell J, et al. Comparative genomics of Canadian epidemic lineages of methicillin-resistant Staphylococcus aureus. J Clin Microbiol 2007;45:1904-11.

14. Mulvey MR, Chiu L, Ismail J, et al. Development of a Canadian standardized protocol for subtyping methicillin-resistant Staphylococcus aureus using pulsed-field gel electrophoresis. J Clin Microbiol 2001;39:3481-85.
15. Mulvey MR, MacDougall L, Cholin B, et al. Community-associated methicillin-resistant Staphylococcus aureus, Canada. Emerg Infect Dis 2005; 11:844-50.

16. Oliveira DC, de Lencastre H. Multiplex PCR strategy for rapid identification of structural types and variants of the mec element in methicillin-resistant Staphylococcus aureus. Antimicrob Agents Chemother 2002;46:2155-61.

17. Tenover FC, Arbeit RD, Goering RV, et al. Interpreting chromosomal DNA restriction patterns produced by pulsed-field gel electrophoresis: Criteria for bacterial strain typing. J Clin Microbiol 1995;33:2233-9.

18. Mulvey MR, Bryce E, Boyd D, et al. Ampler class A extendedspectrum beta-lactamase producing Escherichia coli and Klebsiella spp. in Canadian Hospitals. Antimicrob Agents Chemother 2004:48:1204-14.

19. Deshpande LM, Fritsche TR, Moet GJ, et al. Antimicrobial resistance and molecular epidemiology of vancomycin-resistant enterococci from North America and Europe: A report from the SENTRY antimicrobial surveillance program. Diagn Microbiol Infect Dis 2007;58:163-70.

20. Nichol KA, McCracken M, DeCorby MR, et al. Comparison of community-associated and health care-associated methicillinresistant Staphylococcus aureus in Canada: Results from CANWARD 2007. Can J Infect Dis Med Microbiol 2009;20(Suppl A):31A-6A.

21. Baudry PJ, McCracken M, Lagacé-Wiens P, Mulvey MR, Zhanel GG, Hoban DJ. Prevalence and characterization of extended-spectrum beta-lactamase-producing Enterobacteriaceae isolated in Canadian hospitals: Results from CANWARD 2007. Can J Infect Dis Med Microbiol 2009;20(SA):43A-8A.

22. Klevens RM, Edwards JR, Richards CL, et al. Estimating healthcare associated infections and deaths in US hospitals, 2002. Pub Health Rep 2007;122:160-6.

23. Fridkin SK, Edwards JE, Tenover FC, et al. Antimicrobial resistance prevalence rates in hospital antibiograms reflect prevalence rates among pathogens associated with hospital-acquired infections. Clin Infect Dis 2001;33:324-30.

24. Huang SS, Yokoe DS, Hinrichsen VL, et al. Impact of routine intensive care unit surveillance cultures and resultant barrier precautions on hospital-wide methicillin-resistant Staphylococcus aureus bacteremia. Clin Infect Dis 2006;43:971-78.

25. Shadel BN, Puzniak LA, Gillespie KN, et al. Surveillance for vancomycin-resistant enterococci: Type, rates costs and implications. Infect Cont Hosp Epid 2006;27:1068-75.

26. Grayson ML, Jarvie LJ, Martin R, et al. Significant reductions in methicillin-resistant Staphylococcus aureus bacteremia and clinical isolates associated with multisite hand hygiene culture change program and subsequent successful statewide roll-out. Med J Aust 2008; 188:633-40.

27. Lewis JS, Herraera M, Wickes B, et al. First report of the emergence of CTX-M-type extended-spectrum $\beta$-lactamases (ESBL) as the predominant ESBL isolated in a US health care system. Antimicrob Agents Chemother 2007;51:4015-21.

28. Castanheira M, Mendes RE, Rhomberg PR, et al. Rapid emergence of bla ${ }_{\text {CTX-M }}$ among enterobacteriaceae in US medical centers: Molecular evaluation from the MYSTIC program (2007). Microb Drug Resist 2008;14:211-6.

29. Levin PD, Fowler RA, Guest C, et al. Risk factors associated with resistance to ciprofloxacin in clinical bacterial isolates from intensive care unit patients. Infect Cont Hosp Epid 2007;28:331-36.

30. Rhomberg PR, Fritsche TR, Sader HS, et al. Antimicrobial susceptibility pattern comparisons among intensive care unit and general ward gram-negative isolates from meropenem yearly susceptibility test information collection program (USA). Diagn Microbiol Infect Dis 2006;56:57-62.

31. Rybak MJ, Leonard SN, Rossi KL, et al. Characterization of vancomycin-heteroresistant Staphylococcus aureus from the metropolitan area of Detroit, Michigan overa 22 year period (1986-2007). Antimicrob Agents Chemother 2008; $46: 2950-54$. 


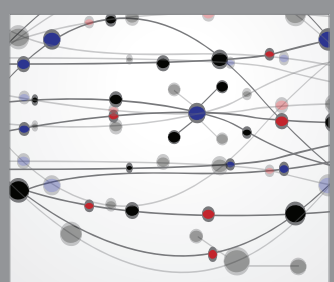

The Scientific World Journal
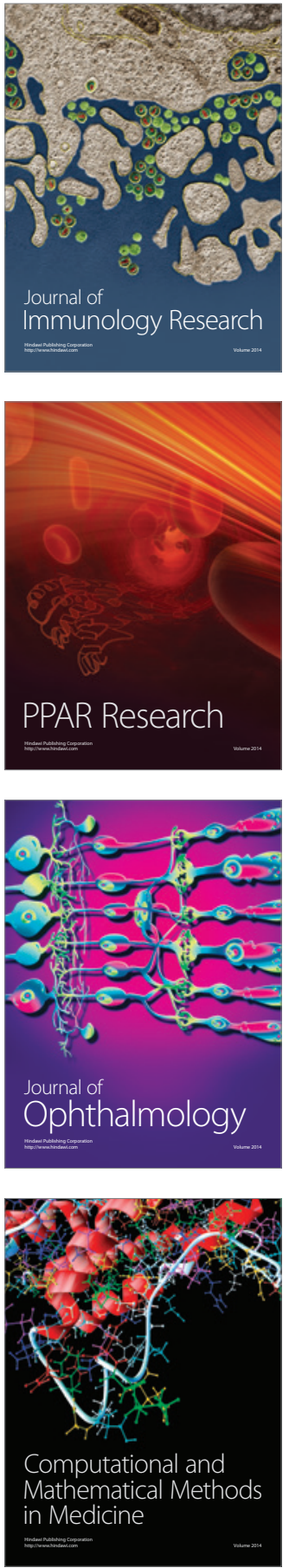

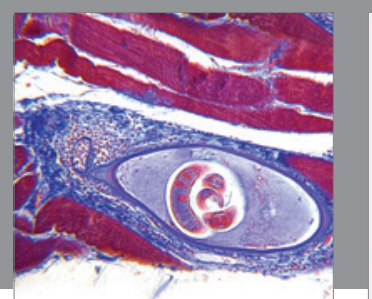

Gastroenterology Research and Practice

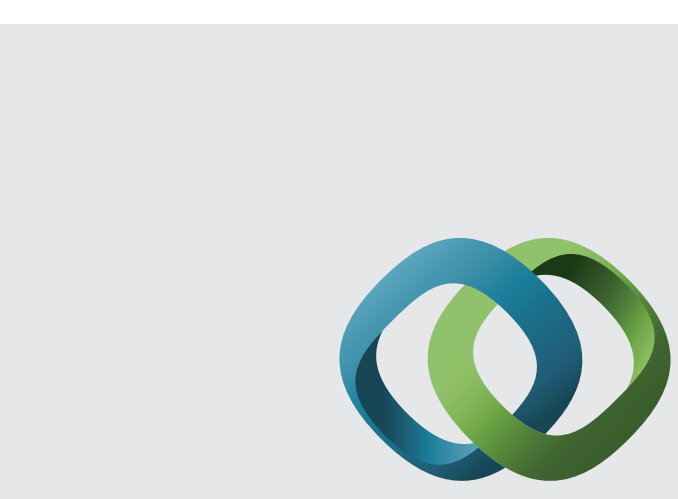

\section{Hindawi}

Submit your manuscripts at

http://www.hindawi.com
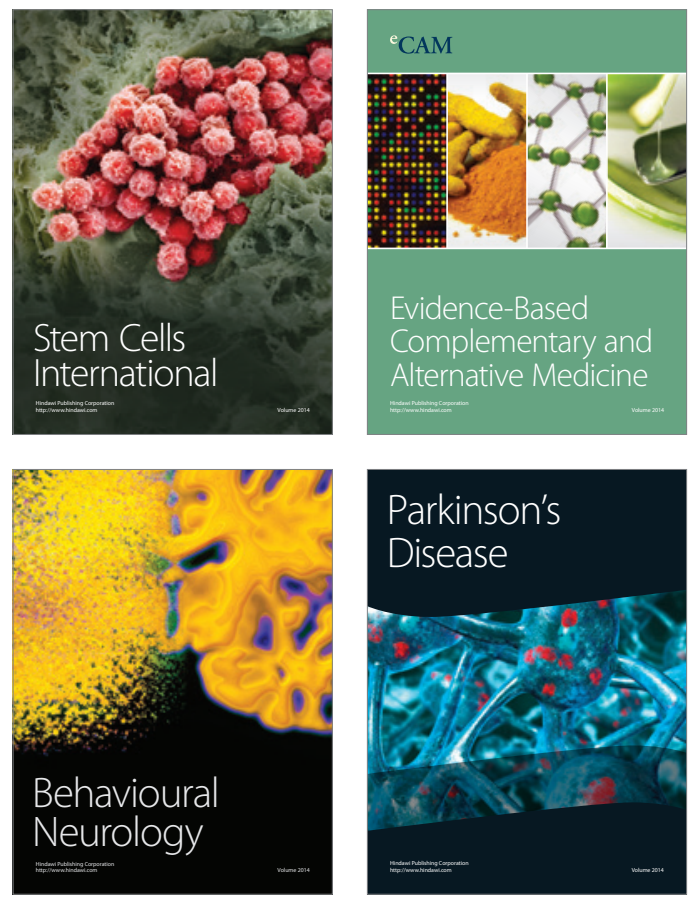
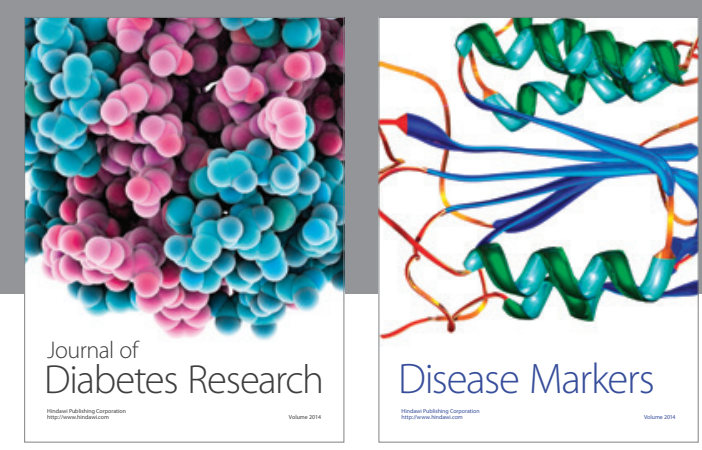

Disease Markers
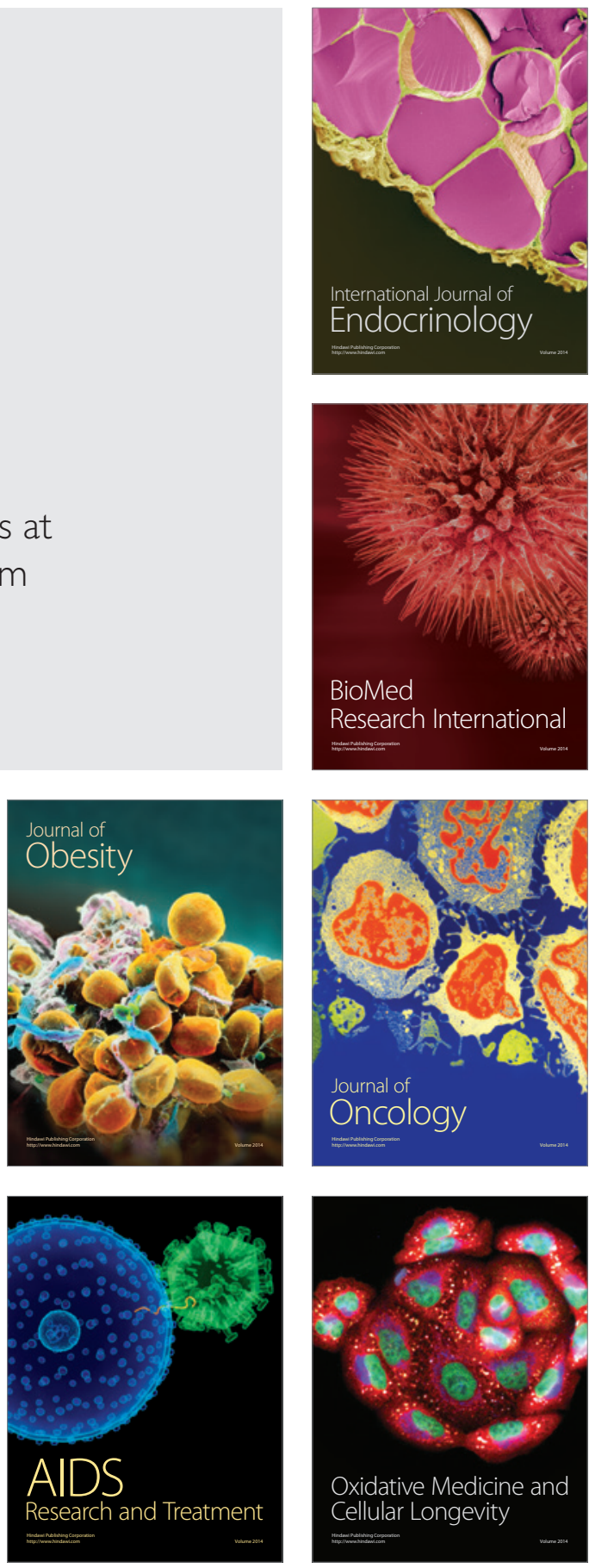